\title{
Preparation and antitubercular activity of lipophilic diamines and amino alcohols
}

\author{
Celso OR Júnior ${ }^{1}$, Mireille le Hyaric ${ }^{1}$, Cristiane F da Costa', Taís A Corrêa ${ }^{1}$, Aline F Taveira', \\ Débora P Araújo', Elaine FC Reis', Maria Cristina S Lourenço ${ }^{2}$, Felipe RC Vicente², \\ Mauro V de Almeida ${ }^{2}+$
}

${ }^{1}$ Departamento de Química, Universidade Federal de Juiz de Fora, Juiz de Fora, MG, Brasil 2Instituto de Pesquisa Clínica Evandro Chagas-Fiocruz, Rio de Janeiro, RJ, Brasil

A series of diamines and amino alcohols derived from 1-dodecanol, 1-tetradecanol, 1,2-dodecanediol and 1,2-tetradecanediol were synthesized and tested for their antitubercular activity. Compounds 3, 8 and 9 were found to be the most active (MIC of $6.25 \mu \mathrm{g} / \mathrm{mL}$ ). Nine other compounds displayed activity against Mycobacterium tuberculosis, with a MIC of $12.5 \mu \mathrm{g} / \mathrm{mL}$.

Key words: tuberculosis - amino alcohols - diamines - lipophilicity

Tuberculosis (TB), a serious disease caused by $M y$ cobacterium tuberculosis, is transmitted by air and can affect all organs of the body, especially the lungs. In case of infection, treatment basically consists of the combination of three medicines: rifampicin, isoniazid and pyrazinamide. If the medications are taken correctly, the chances of cure reach $95 \%$. Interruption of treatment causes the emergence of drug resistant strains of TB, which is the main world-wide concern regarding the disease (WHO 2009). Multidrug resistant TB, which is resistant to isoniazid and rifampin, is a particularly dangerous form of TB, and its spread could lead to a new wave of a virtually incurable disease throughout the entire world (WHO 2009).

Several antitubercular compounds with different mechanisms of action have been synthesised in recent years. Their targets include fatty acid biosynthesis, protein synthesis, DNA-based processes, cell wall synthesis and energy metabolism pathways (Zhang et al. 2006, Janin 2007). Ethambutol, an amino alcohol first reported by Wilkinson et al. in the early 1960s, is one of the few long-known and reliable first-line antimycobacterial chemotherapeutic agents and acts as an inhibitor of cell wall biosynthesis (Janin 2007, Ralambomanana et al. 2008). Glycosylated amino alcohols and amines are known for their antimycobacterial activity (Katiyar et al. 2005). We have previously described the synthesis and anti-TB activity of glycosylated derivatives of $\mathrm{N}$-alkylated diamines or amino alcohols (De Almeida et al. 2007, Taveira et al. 2007). In the present work, we investigate the anti-TB activity of a series of $\mathrm{N}$-alkylated diamines and amino alcohols obtained from fatty alcohols (Figure).

Financial support: CAPES, CNPq, FAPEMIG

+Corresponding author: mauro.almeida@ufjf.edu.br

Received 5 December 2008

Accepted 24 April 2009

\section{MATERIALS AND METHODS}

Chemistry - Compounds 1-10 were prepared in two steps from 1-dodecanol or 1-tetradecanol using a methodology previously described (Reis et al. 2008). The alcohol was first treated with mesyl chloride in methylene chloride and pyridine to furnish the corresponding mesylate. The crude mesylates were treated with the amino alcohols (2-aminoethanol, 3-amino-1-propanol, diethanolamine or 2-amino-2-methyl-1-propanol) or diamines (ethylenediamine or 1,3-propanediamine) in ethanol at reflux to furnish the desired amino alcohols 1-8 and diamines 9 and 10 with a $42-98 \%$ yield in two steps. Compounds $11-22$ were obtained with a $40-90 \%$ yield using a similar protocol starting from 1,2-dodecanediol or 1,2-tetradecanediol.

In vitro assay - The antitubercular activity of the tested compounds was determined by incorporating decreasing concentrations into a culture of $M$. tuberculosis H37Rv (ATCC 27294) in Middlebrook 7H9 agar medium using the Microplate Alamar Blue Assay (Collins \& Franzblau 1997). MIC values represent means of three separate experiments. Ethambutol was used as the reference compound. $\log P$ was calculated using ACDLABS software.

\section{RESULTS AND DISCUSSION}

The best results (MIC $=6.25 \mu \mathrm{g} / \mathrm{mL}$ ) were obtained for compounds 3,8 and 9, which were derived from dodecanol and tetradecanol (Table). Compounds 1 and 11, derived from diethanolamine, displayed the lowest activity of all the tested compounds, with a MIC $=50 \mu \mathrm{g} / \mathrm{mL}$.

Comparing all the tested compounds individually, we could not find a clear correlation between lipophilicity $(\log P)$ (Table) and activity. However, when comparing compounds 11-22 prepared from diols, with compounds 1-10 obtained from monoalcohols, it appears that, with chain length and functional groups being the same, all diol derivatives were less lipophilic and less active than their monoalcohol analogues. 

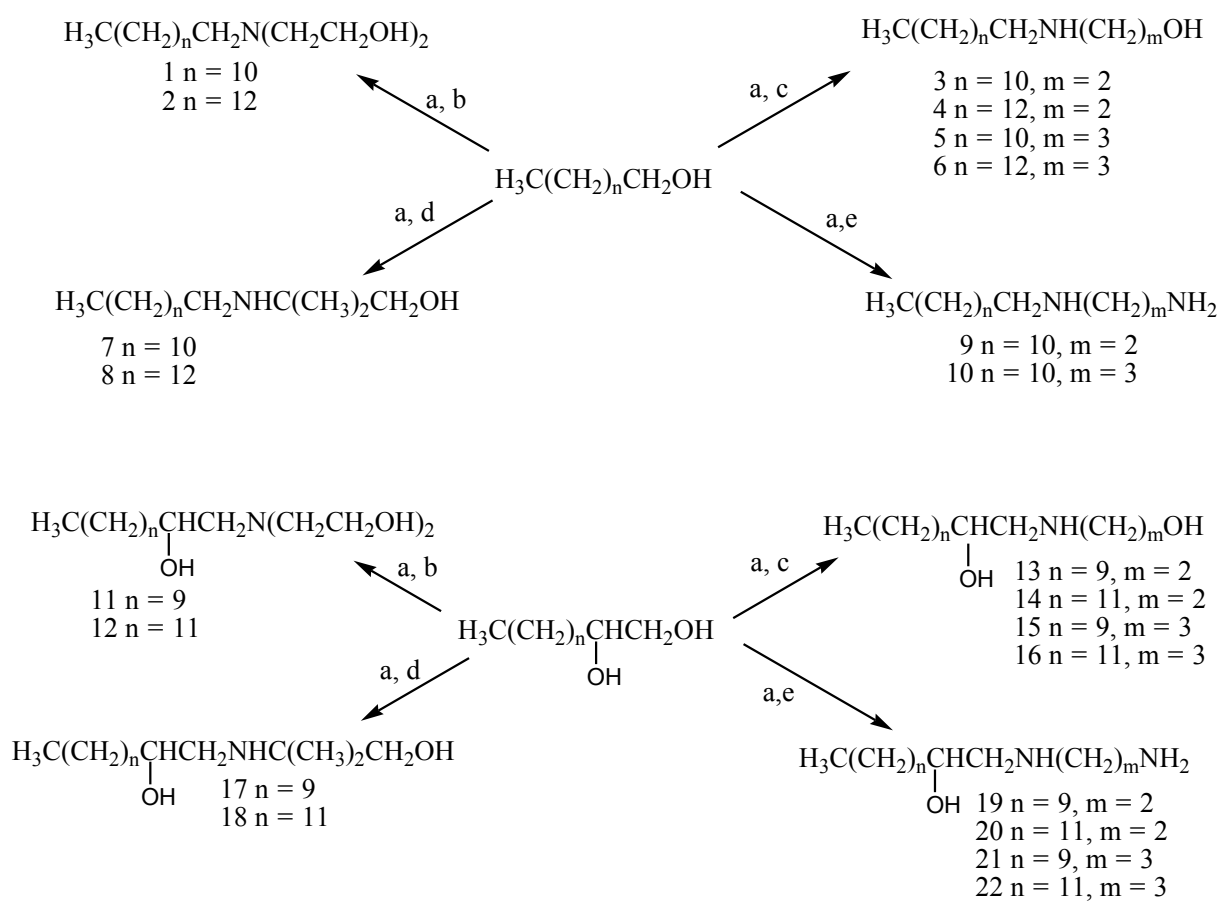

Reagents and conditions: a: 1-dodecanol, 1-tetradecanol, 1,2-dodecanediol or 1,2-tetradecanediol, $\mathrm{CH}_{2} \mathrm{Cl}_{2}, \mathrm{CH}_{3} \mathrm{SO}_{2} \mathrm{Cl}_{2}$ py, $0^{\circ} \mathrm{C}, 20 \mathrm{~h}$; b: $\mathrm{NH}\left(\mathrm{CH}_{2} \mathrm{CH}_{2} \mathrm{OH}\right)_{2}, \mathrm{EtOH}, 80^{\circ} \mathrm{C}, 24 \mathrm{~h}$; c: $\mathrm{NH}_{2}\left(\mathrm{CH}_{2}\right)_{2} \mathrm{OH}$ or $\mathrm{NH}_{2}\left(\mathrm{CH}_{2}\right)_{3} \mathrm{OH}, \mathrm{EtOH}, 80^{\circ} \mathrm{C}, 24 \mathrm{~h} ; \mathrm{d}: \mathrm{NH}_{2} \mathrm{C}^{2}\left(\mathrm{CH}_{3}\right)_{2} \mathrm{CH}_{2} \mathrm{OH}, \mathrm{EtOH}, 80^{\circ} \mathrm{C}, 24 \mathrm{~h}$; e: $\mathrm{NH}_{2}\left(\mathrm{CH}_{2}\right)_{2} \mathrm{NH}_{2}$ or $\mathrm{NH}_{2}\left(\mathrm{CH}_{2}\right)_{3} \mathrm{NH}_{2}, \mathrm{EtOH}, 80^{\circ} \mathrm{C}, 24 \mathrm{~h}$.

TABLE

Antitubercular activity of compounds $1-22$

\begin{tabular}{|c|c|c|c|c|c|c|c|c|}
\hline Compound & $\begin{array}{c}\mathrm{MIC} \\
\mu \mathrm{g} / \mathrm{mL}\end{array}$ & $\log P$ & Compound & $\begin{array}{c}\mathrm{MIC} \\
\mu \mathrm{g} / \mathrm{mL}\end{array}$ & $\log P$ & Compound & $\begin{array}{c}\text { MIC } \\
\mu \mathrm{g} / \mathrm{mL}\end{array}$ & $\log P$ \\
\hline 1 & 50.0 & 5.13 & 9 & 6.25 & 4.69 & 17 & 25.0 & 4.32 \\
\hline 2 & 12.5 & 6.16 & 10 & 25.0 & 5.06 & 18 & 12.5 & 5.38 \\
\hline 3 & 6.25 & 4.88 & 11 & 50.0 & 4.02 & 19 & 25.0 & 3.44 \\
\hline 4 & 12.5 & 5.94 & 12 & 25.0 & 5.08 & 20 & 25.0 & 4.50 \\
\hline 5 & 12.5 & 5.00 & 13 & 25.0 & 3.62 & 21 & 12.5 & 3.81 \\
\hline 6 & 12.5 & 6.07 & 14 & 12.5 & 4.69 & 22 & 12.5 & 4.88 \\
\hline 7 & 12.5 & 5.57 & 15 & 25.0 & 3.75 & ethambutol & 3.12 & - \\
\hline 8 & 6.25 & 6.64 & 16 & 25.0 & 4.81 & - & - & - \\
\hline
\end{tabular}

Comparing the length of the aliphatic chain, compounds 3 and 9 were the only compounds displaying better activity than their more lipophilic tetradecyl analogues 4 and $10(\mathrm{MIC}=25.0 \mu \mathrm{g} / \mathrm{mL})$. Compounds 2, 8, 12, 14, 18 and 20 were more efficient or as efficient as their less lipophilic dodecyl analogues 1, 7, 11, 13, 17 and 19.

Considering the presence of branching, the activities of amino alcohols 7, 8, 17 and 18 were compared to the activities of their linear analogues 5, 6, 15 and 16. It appears that branching enhances the activity of the tetradecyl derivatives but not of the dodecyl derivatives.

Propanediamine derivatives 21 and $22(\mathrm{MIC}=12.5 \mu \mathrm{g} /$ $\mathrm{mL}$ ) were more lipophilic and more active than their amino alcohol analogues 15 and $16(\mathrm{MIC}=25.0 \mu \mathrm{g} / \mathrm{mL})$, but ethylenediamine derivative $20(\mathrm{MIC}=25.0 \mu \mathrm{g} / \mathrm{mL})$ was less active than its alcohol analogue $14(\mathrm{MIC}=12.5 \mu \mathrm{g} / \mathrm{mL})$.

Cytotoxicities of amino alcohols 2, 3, 4, 6, 8, 14 and 16 have been determined in previous work (Taveira et al. 2007, Reis et al. 2008), which showed that compounds 3 and 8 display low toxicity $(0.5 \mu \mathrm{g} / \mathrm{mL})$ while compounds $2,4,6,14$ and 16 do not display significant cytotoxicity.

In conclusion, this work describes the antitubercular evaluation of several diamines and amino alcohols derivatives containing an alkyl chain. Three of these compounds (3, 8 and 9) displayed good activity against M. tuberculosis. The results shown here, together with 
previously published data, provide evidence that $\mathrm{N}$-alkylated diamines or amino alcohols could serve as good starting points in the search for new lead compounds.

\section{REFERENCES}

Collins L, Franzblau SG 1997. Microplate Alamar blue assay versus BACTEC 460 system for high-throughput screening of compounds against Mycobacterium tuberculosis and Mycobacterium avium. Antimicrob Agents Chemother 41: 1004-1009.

De Almeida MV, Le Hyaric M, Amarante GW, Silva Lourenço MC, Lima Brandão ML 2007. Synthesis of amphiphilic galactopyranosyl diamines and amino alcohols as antitubercular agents. Eur J Med Chem 42: 1076-1083.

Janin YL 2007. Antituberculosis drugs: ten years of research. Bioorg Med Chem 15: 2479-2513.

Katiyar D, Tiwari VK, Tewari N, Verma SS, Sinha S, Gaikwad A, Srivastava A, Chaturvedi V, Srivastava R, Srivastava BS, Tripathi RP 2005. Synthesis and antimycobacterial activities of glycosylated amino alcohols and amines. Eur J Med Chem 40: 351-360.

Ralambomanana DA, Ramilison DR, Rakotohova AC, Maugein J,
Pélinsky L 2008. Synthesis and antitubercular activity of ferrocenyl diaminoalcohols and diamines. Bioorg Med Chem 16: 9546-9553.

Reis EFC, Júnior COR, Alves LL, Ferreira AP, De Almeida MV 2008. Synthesis and immunosuppressive activity of lipophilic amino alcohols and diamines. Chem Biol Drug Des 72: 596-598.

Taveira AF, Le Hyaric M, Reis EFC, Araújo DP, Ferreira AP, De Souza MA, Alves LL, Silva Lourenço MC, Vicente FRC, De Almeida MV 2007. Preparation and antitubercular activities of alkylated amino alcohols and their glycosylated derivatives. Bioorg Med Chem 15: 7789-7794.

Wilkinson RG, Shepherd RG, Thomas JP, Baughn C 1961. Stereospecificity in a new type of synthetic antituberculous agent. $J \mathrm{Am}$ Chem Soc 83: 2212-2213.

WHO - World Health Organization 2009. Fact sheets on tuberculosis. Avalilable from: http://www.who.int/tb/en/.

Zhang Y, Post-Martens K, Denkin S 2006. New drug candidates and therapeutic targets for tuberculosis therapy. Drug Discov Today 11: 21-27. 